\title{
Stump Appendicitis and the Critical View of Safety
}

\section{Editorial}

We present a case of a 27 -year-old gentleman who presented to our hospital. He underwent a laparoscopic appendectomy six months previously. His surgery was complicated by a post-operative collection which was drained under CT guidance. He had no past medical history and was on no regular medication. He presented with a one day history of Right Iliac Fossa (RIF) pain. The pain was constant, dull in nature and was progressively getting worse. It was associated with anorexia, nausea and two episodes of vomiting. He denied rigors, diarrhoea, constipation or urinary tract symptoms. On examination, he was febrile $\left(39^{\circ} \mathrm{C}\right)$, his abdomen was soft but tender in the RIF with guarding. His laboratory investigations were significant for a C-reactive protein level of $32 \mathrm{mg} / \mathrm{L}$ and a white cell count of $14 \times 10^{9} / \mathrm{L}$. The differential included a post-operative collection. He underwent a CT scan of his abdomen and pelvis.

The CT scan showed a thickened oedematous wall of the inferior pole of the cecum along with an appendicular stump which was acutely inflamed (Figure 1). The patient underwent laparoscopy in which an acutely inflamed appendicular stump was seen (Figure $2)$. It was successfully resected. The patient recovered well and was discharged home on post-operative day 2. He has reported no further complications at his 3-month review clinic.

Acute appendicitis is one of the most common indications for emergency abdominal surgery accounting for approximately $1 \%$ of all surgical operations. Common post-operative complications include wound infections, intra-abdominal infections and adhesions. The first two cases of stump appendicitis were reported by Rose et al in 1945 [1]. The precise pathogenesis remains poorly understood, however it is postulated that obstruction of the remaining stump lumen by a fecolith may be the causative factor. This increases intraluminal pressure, impairs venous drainage and allows subsequent bacterial infection. There are approximately 62 cases reported in the literature although most authors would suggest that it is underreported. Most reported cases do not have radiographic or photo-documentation of

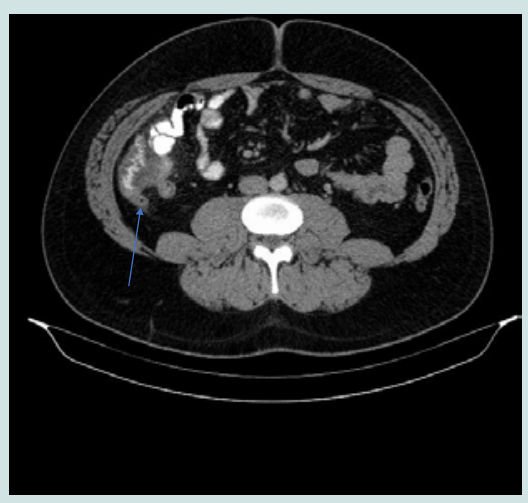

Figure 1: CT scan showing appendicular stump.

\section{Journal of} Surgery

\section{Eoghan P. Burke*, Salama M, Saeed M, Ahmed I}

\section{Department of Surgery, Ireland}

\section{*Address for Correspondence}

Eoghan P. Burke, Department of Surgery, Our Lady of Lourdes Hospital, Drogheda, Ireland, E-ma.il: eoghanburke@rcsi.ie

Submission: 26 June, 2019

Accepted: 03 July, 2019

Published: 05 July, 2019

Copyright: () 2019 Burke EP. This is an open access article distributed under the Creative Commons Attribution License, which permits unrestricted use, distribution, and reproduction in any medium, provided the original work is properly cited.

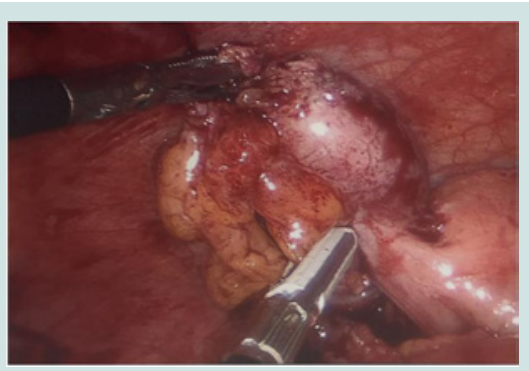

Figure 2: Intraoperative image from completion appendectomy. Identifies appendicular stump measuring greater than the recommended $5 \mathrm{~mm}$.

the appendicular stump being acutely inflamed.

Stump appendicitis was traditionally felt to be more common following a laparoscopic appendectomy secondary to the absence of tactile feedback and a 3-dimensional perspective. However, the most extensive review to date on the topic conducted by Subramanian et al disproved this theory and found it to be more common in open appendectomies [2].

Multiple factors are thought to contribute to incomplete appendectomy, the most important being incorrect identification of the surgical anatomy. This led Subramanian et al to propose A Critical View of Safety (CVS) for appendectomy similar to that famously developed by Strasberg et al in 1995 for laparoscopic cholecystectomy [2]. This CVS for appendectomy centres on correctly identifying the appendicular-cecal junction and thus the appendicular base. The CVS is achieved when the taenia libera is seen clearly on the surface of the cecum running into the base of the appendix with the appendix elevated and displaced inferiorly and the terminal ileum in the foreground at laparoscopy. In this position, the mesoappendix can then be divided appropriately and the base clearly identified.

The length of the appendicular stump left behind is crucial. Most authors recommend leaving less than $5 \mathrm{~mm}$ behind. A stump of greater than $5 \mathrm{~mm}$ is thought to be large enough to act as a reservoir for a fecolith [3]. In figure 3 we depict an intraoperative image from our patient's initial laparoscopic appendectomy (Figure 3). We can see that the CVS has not been identified. This led the surgeon to incorrectly assume he had identified the appendicular base leading him to leave a stump of greater than $5 \mathrm{~mm}$ behind. 


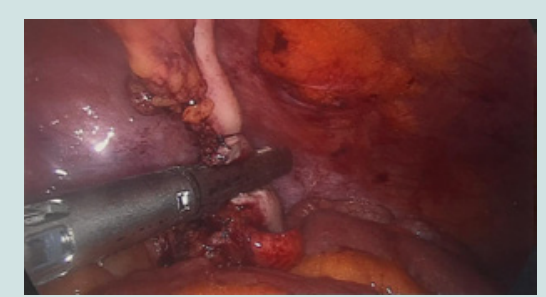

Figure 3: Intraoperative image from initial laparoscopic appendectomy. Endo GIA fired too high secondary to inadequate visualisation of appendicular base.

Stump appendicitis continues to pose a diagnostic dilemma both for surgeons and emergency department clinicians. We quickly remove acute appendicitis from our differential diagnosis list in patients presenting with RIF pain when we learn they have had previous appendectomy. The temporal relationship between index appendectomy and onset of stump appendicitis is hugely variable ranging from weeks to years which further complicates matters.

We can aim to limit the risk of stump appendicitis by encouraging surgeons to adopt the CVS for appendectomy suggested by Subramanian et al.

\section{References}

1. Shah T, Gupta R, Karkee R, Agarwal C (2017) "Recurrent pain abdomen following appendectomy: Stump Appendicitis, a surgeon's dilemma". Clin Case Rep 5: 215-217.

2. Subramanian A, Liang M (2012) "A 60-year literature review of stump appendicitis: the need for a critical view". Am J Surg 203: 503-507.

3. Essenmacher A, Nash E, Walker S, Pitcher G, Buresh C, et al. (2018) "Stump Appendicitis". Clin Pract Cases Emerg Med 2: 211-214. 